\title{
Immobilization of myoglobin in sodium alginate composite membranes
}

\author{
Katia Cecília de Souza Figueiredo ${ }^{1 *}$, Wilbert van de Ven², Matthias Wessling², \\ Tito Lívio Moitinho Alves ${ }^{1}$ and Cristiano Piacsek Borges ${ }^{1}$
}

\author{
'Instituto Alberto Luiz Coimbra de Pós-Graduação e Pesquisa de Engenharia - COPPE, \\ Universidade Federal do Rio de Janeiro - UFRJ, Rio de Janeiro, RJ, Brazil \\ ${ }^{2}$ Membrane Technology Group, Science and Technology, University of Twente - UT, \\ Meander, AE Enschede, The Netherlands \\ *katia@deq.ufmg.br
}

\begin{abstract}
The immobilization of myoglobin in sodium alginate films was investigated with the aim of evaluating the protein stability in an ionic polymeric matrix. Myoglobin was chosen due to the resemblance to each hemoglobin tetramer. Sodium alginate, being a natural polysaccharide, was selected as the polymeric matrix because of its chemical structure and film-forming ability. To improve the mechanical resistance of sodium alginate films, the polymer was deposited over the surface of a cellulose acetate support by means of ultrafiltration. The ionic crosslink of sodium alginate was investigated by calcium ions. Composite membrane characterization comprised water swelling tests, water flux, SEM images and UV-visible spectroscopy. The electrostatic interaction between the protein and the polysaccharide did not damage the UV-visible pattern of native myoglobin. A good affinity between sodium alginate and cellulose acetate was observed. The top layer of the dense composite membrane successfully immobilized Myoglobin, retaining the native UV-visible pattern for two months.
\end{abstract}

Keywords: myoglobin, sodium alginate, immobilization, composite membrane, cellulose acetate.

\section{Introduction}

Facilitated transport membranes have been investigated as an alternative to increase flux and selectivity of ordinary films ${ }^{[1]}$. These special properties are achieved by adding a carrier to the membrane, so that the desired component is preferentially transported from the feed to the permeate stream. The reaction between the solute and the carrier must be reversible. The process can be described as follows: 1) the solute binds to the carrier on the feed/membrane interface, 2) the complex diffuses through the membrane due to a concentration gradient, 3) the solute is released on the membrane/permeate interface and the carrier is regenerated. The transport mechanism for fixed site carriers is similar to the mobile ones, but the solute should be able to jump from one site to the other until it reaches the membrane/permeate interface, where it is released. Due to this reactive mechanism, the effective transport of solutes can only be achieved for low partial pressure of the desired component, otherwise it would cause the saturation of the carrier sites. Therefore, one of the most promising applications of such membranes is in the air separation, due to the similar physical properties of its components. The high demand for pure oxygen and oxygen-enriched air has motivated a large number of studies on oxygen facilitated transport membranes ${ }^{[2]}$.

The use of the synthetic oxygen carriers in supported liquid membranes was extensively studied in the last 30 years and the results were remarkable to the understanding of the solute transport mechanism through the membrane. However, the lack of stability in long-term applications due to the evaporative loss of solvent and oxidation of the carrier limited the advance of this approach. Alternatively, new morphologies have been tested, as the encapsulation of the carrier in a polymeric shell ${ }^{[3]}$ or the use of a polymeric matrix to stabilize the carrier ${ }^{[4-6]}$. High selectivities have been reported but the instability of such membranes remains unsolved and there is still a need for the development of an efficient process to replace the energy-intense cryogenic distillation.

The regained interest in the use of the hemoproteins in oxygen facilitated transport membranes relies on the role of the globin moiety to prevent the autoxidation of these biocarriers ${ }^{[7]}$ and the development of the molecular biology tools, which allows the change in the aminoacids sequence to provide more stable oxygen carriers ${ }^{[8]}$. The choice of myoglobin to produce oxygen facilitated transport membranes was based on the fact that the protein is a single-site oxygen biocarrier and, thus, simpler than hemoglobin structure. Sodium alginate was chosen as the polymeric matrix for the immobilization of myoglobin because of its industrial and upcoming biotechnological applications as thickening and emulsifying agent used in food formulations. Also it suffers gelation in a quite gentle way in the presence of ions such as calcium.

Being an anionic copolymer of 1,4-linked- $\beta$-D-mannuronic $\operatorname{acid}(\mathrm{M})$ and $\alpha$-L-guluronic acid $(\mathrm{G})$ residues, alginate forms a gel due to the stacking of guluronic acid blocks, which have a particular diamond shape, ideal for the cooperative binding of calcium and other ions ${ }^{[9]}$. The selective ion binding characteristic, which forms a structure well-known 
as the egg-box model, makes possible the immobilization of biomolecules and living cells in this polysaccharide, by tailoring the water-swelling behavior of the gel. This potential feature was exploited here aiming the stabilization of the protein inside the solid membrane. In addition to it, it is also worthwhile to consider that recent research in sodium alginate ultrafiltration shows that this polyelectrolyte has different conformations in aqueous solution as a function of the ionic environment ${ }^{[10]}$. Therefore, regarding to the synthesis of a dense composite membrane, the top layer density could be controlled by adding non-gelling ions to the polymeric aqueous solution.

In this work, the immobilization of myoglobin in a sodium alginate (SA) matrix was investigated aiming the stabilization of the protein in the polymeric membrane. In order to circumvent the lack of mechanical strength of SA films, composite dense membranes were tested. The use of a thin active polymeric layer in which both the oxygen uptake and release can be performed in one single stage will improve process efficiency and economy ${ }^{[11]}$.

\section{Experimental}

\subsection{Materials}

Myoglobin from horse heart (Fluka ${ }^{\circledR}$ ), minimum $90 \%$ of purity, was obtained in the metmyoglobin form $\left(\mathrm{Fe}^{3+}\right)$. Sodium alginate medium viscosity and Sephadex ${ }^{\circledR} \mathrm{G} 25$ were acquired from Aldrich ${ }^{\circledR} . \mathrm{KCl}, \mathrm{CaCl}_{2}, \mathrm{FeCl}_{2}$ and $\mathrm{Na}_{2} \mathrm{~S}_{2} \mathrm{O}_{4}$ were used as received. Centripep device (Millipore ${ }^{\circledR}$, Bedford, MA) and ultrafiltration cellulose acetate substrate (MWCO $100 \mathrm{kDa}, \mathrm{Nadir}^{\circledR}$ ) were used in protein concentration and as a porous support on the composite membrane.

\subsection{Myoglobin activation}

Metmyoglobin $\left(\mathrm{Fe}^{3+}\right)$ was activated, i. e., reduced to $\mathrm{Fe}^{2+}$, by reacting the protein aqueous solution and sodium dithionite. Oxymyoglobin $\left(\mathrm{Fe}^{2+}\right.$ bound to $\left.\mathrm{O}_{2}\right)$ was separated from metmyoglobin by means of a chromatographic method using Sephadex ${ }^{\circledR}$ G25-filled column at room temperature. Once the fraction was purified, its concentration was adjusted by means of centrifugation on a Centripep device using an ultrafiltration filter with MWCO of $5 \mathrm{kDa}$, at $1,800 \mathrm{~g}$ and $4^{\circ} \mathrm{C}$.

\subsection{Integral membrane preparation}

Sodium alginate, $\mathrm{SA}$, and $\mathrm{KCl}$ were dissolved in distilled water in room temperature. Myoglobin was added to the solution in the desired amount. The mixture was gently stirred in order to dissolve the macromolecule with no damage to the structure. The mass ratio between $\mathrm{Mb}$ and $\mathrm{SA}$ was varied from 0 to $2 \mathrm{~g} / \mathrm{g}$. The mixture was poured into a Petri dish and dried at $20^{\circ} \mathrm{C}$, for 15 hours. This method is known as solvent evaporation. The final contents of $\mathrm{SA}$ and $\mathrm{KCl}$ on the casting solution were $1.0 \mathrm{wt} \%$ and $10 \mathrm{mM}$, respectively. The $\mathrm{pH}$ of the casting solution was 6.5. Membranes were pelled of the plate and stored in a desiccator.

\subsection{Composite membrane preparation}

The preparation of composite membranes was performed with the aim of increasing the mechanical strength of SA films. Sodium alginate was deposited over an ultrafiltration cellulose acetate substrate (MWCO $100 \mathrm{kDa}$ ) in order to prepare composite membranes. The choice of the ultrafiltration cellulose acetate support was based on its similarity with sodium alginate. The porous support was prior characterized by the ultrafiltration of pure water, alginate $(0.1 \mathrm{wt} \%)$ and myoglobin $(0.1 \mathrm{wt} \%)$ aqueous solutions, at $20^{\circ} \mathrm{C}$, feed to permeate pressure difference of 3 bar and $700 \mathrm{rpm}$.

Composite membrane preparation was based on the pore blockage of the cellulose acetate support by means of the ultrafiltration of SA aqueous solution $(0.1 \mathrm{wt} \%)$ containing $10 \mathrm{mM} \mathrm{KCl}$. The addition of the saline solution can decrease the space between the anionic copolymer. The experimental set up was composed by a dead-end filtration tank with $36.3 \mathrm{~cm}^{3}$ of effective area, in which the $\mathrm{SA} / \mathrm{KCl}$ aqueous solution was added. The UF support was placed on the bottom of the tank. Once the pores were blocked, which was measured by the reduction on permeate flux, oxymyoglobin or the crosslinking ion $\left(\mathrm{Ca}^{2+}\right.$ or $\mathrm{Fe}^{2+}$ aqueous solution) was added to the filtration tank. Composite membranes were then dried at $20^{\circ} \mathrm{C}$ overnight and stored in a desiccator.

\subsection{Membrane characterization}

\subsubsection{Integral membranes}

Membrane thickness was determined by means of a micrometer. The result was the average of at least 20 measures.

Myoglobin physiological form in the dense film was investigated in an UV-visible spectroscope (UV mini 1240, Shimadzu, Tokyo, Japan). Strips of $(0.4 \times 2) \mathrm{cm}^{2}$ of dense membranes were placed in the cuvette. SA films with no added-myoglobin were used as the reference. This technique was used qualitative in order to evaluate the iron oxidation state of the immobilized myoglobin film, since $\mathrm{Fe}^{2+}$ and $\mathrm{Fe}^{3+}$ show different UV-visible absorption spectra. For instance, the Soret peak is $409 \mathrm{~nm}$ for $\mathrm{Fe}^{3+}$, while it is at $418 \mathrm{~nm}$ for $\mathrm{Fe}^{2+}$ bound to oxygen.

Water swelling degree tests were conducted to characterize the membranes. Membrane strips were placed in a Petri dish with water, at $20^{\circ} \mathrm{C}$. They were removed 48 hours later, had their weight determined and were dried in a vacuum oven, at $30^{\circ} \mathrm{C}$. The swelling degree (SD) was calculated according to Equation 1, in which $\mathrm{m}_{\text {wet }}$ and $\mathrm{m}_{\text {dry }}$ are the weight of wet and dried membrane, respectively.

$$
S D=\frac{\left(m_{w e t}-m_{d r y}\right) * 100}{m_{d r y}}
$$

\subsubsection{Composite membranes}

The characterization of composite SA membranes comprised vapor water swelling tests, pure water flux and scanning electron microscopy.

Vapor water swelling degree of the integral and composite SA membrane was evaluated by placing the samples in a closed recipient containing liquid water in the bottom, as described elsewhere ${ }^{[12]}$. Samples were cut in $(2 \times 2) \mathrm{cm}^{2}$, had their dry weight measured and were placed in a petri dish, which was transferred to the recipient, which was closed for 48 hours, at $20^{\circ} \mathrm{C}$. After that, they were removed from the recipient and had their wet weight determined. The swelling degree (SD) was calculated according to Equation 1. 
Pure water flux through the composite SA membranes was determined in filtration experiments conducted in a $3.14 \mathrm{~cm}^{2}$ area cell. Milli-Q water was filtrated at $3 \mathrm{bar}$, $20{ }^{\circ} \mathrm{C}$ and $700 \mathrm{rpm}$. The permeate weight was measured in time intervals of 15 minutes and the corresponding flux was calculated.

The composite membrane morphology was characterized by scanning electron microscopy, SEM (JEOL, Tokyo, Japan). Samples were freeze-dried in liquid nitrogen, cut and coated by gold sputtering of the surface.

In addition to it, the amounts of alginate and myoglobin retained by the UF support were investigated by spectroscopic analysis. On the first case, the polysaccharide was quantified by the Dubois technique ${ }^{[13]}$, while the protein quantification was conducted by means of the absorption on the Soret region, by the coefficient of extinction ${ }^{[14]}$.

\section{Results and Discussion}

\subsection{Integral membranes}

The addition of $\mathrm{KCl}$ was investigated in order to assure a denser layer, since the polysaccharide chains are less extended in the presence of such non-gelling ions ${ }^{[10]}$. Red and defect-free membranes were obtained. The average thickness of the films was $30 \mu \mathrm{m}$. Once the $\mathrm{pH}$ of the casting solution was 6.5 , SA was negatively charged while myoglobin was positively charged, since the protein $\mathrm{pI}$ ranges from 7.0 to $7.4^{[15]}$. These data suggested that the main interaction between the polysaccharide and the protein was electrostatic. As the electrostatic is a strong interaction, it could lead to protein denaturation, which is usually also associated with decrease in the ability to carry oxygen. On the other hand, the electrostatic interaction may act as a stabilizer of the ionic charged aminoacids that composes the macromolecule.

This dubious behavior was investigated by means of an UV-visible spectroscopy of the films. Being a hemoprotein macromolecule, myoglobin presents a specific UV-visible pattern, which is frequently used in order to infer the physiological form of this protein. Such data is able to inform about the iron microenvironment, but it is related to the prosthetic group of the protein ${ }^{[16]}$.

The spectroscopic analysis of the dense membrane is presented in Figure 1. Membranes with no protein were used as reference. The absorption peaks at 418 (Soret), 542 and $581 \mathrm{~nm}$ were equivalent to the oxymyoglobin UV-visible pattern $^{[15]}$ and showed that the protein active site (Soret region) was retained in the polysaccharide matrix. The absorbance scan of these membranes was repeated once a week for two months and no change on the standard pattern was noticed. These results indicated that the immobilization of the protein in a saline polysaccharide film did not show changes in the primary structure of the macromolecule. A detailed study should be carried in order to evaluate the protein tertiary and quaternary structures, by means of circular dichroism, for instance.

Water swelling degree tests of integral dense membranes were conducted to evaluate the interaction of $\mathrm{SA}$ and $\mathrm{Mb}$. As myoglobin is positively charged in the $\mathrm{pH}$ of 6.5 , it could work as an ionic crosslinker for SA membranes. However, the membranes had high swelling degree, with

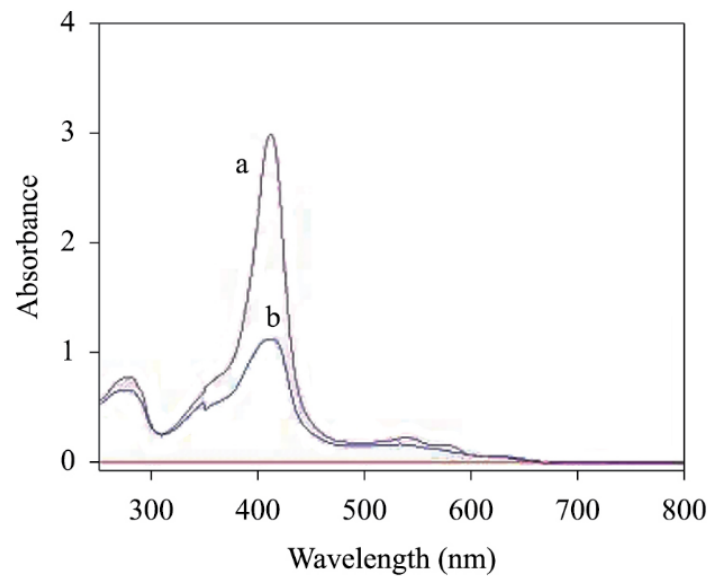

Figure 1. UV-visible spectra of SA integral membrane containing Mb. (a) $\mathrm{Mb} / \mathrm{SA}=2 \mathrm{~g} / \mathrm{g}$, (b) $\mathrm{Mb} / \mathrm{SA}=1 \mathrm{~g} / \mathrm{g}$.

lose of its shape due to the partial dissolution of the strips. These results showed that the interaction of the polymer and protein with water was stronger than between them. Therefore, myoglobin was considered a poor crosslinker for alginate molecules. This can be reasoned in terms of protein shape, which is a globular one, and consequently hard to act as crosslinker.

\subsection{Composite membranes}

Pure water flux through the commercial ultrafiltration support was $(38+2) \times 10 \mathrm{~L} / \mathrm{h} \cdot \mathrm{m}^{2}$, in accordance with the range expected from the manufacturer, from 200 to $400 \mathrm{~L} / \mathrm{h} \cdot \mathrm{m}^{2}$. Operating conditions were $20^{\circ} \mathrm{C}, 3 \mathrm{bar}, 700 \mathrm{rpm}$. The characterization of SA and myoglobin fluxes through the UF support can be visualized in Figures $2 \mathrm{a}$ and $\mathrm{b}$, respectively. The fluxes through the substrate decreased with time, denoting that the pores were blocked by the solutes, which characterizes support fouling. Regarding the sodium alginate aqueous solution (Figure 2a), the triplicates showed low deviation. The decrease on the permeate flux was ascribed to the increase on the fouling layer by pore blockage mechanism, which increased the mass transfer resistance. A similar system was investigated in order to allow the ultrafiltration of proteins with similar molecular weight and the results showed that membrane selectivity was significantly changed by $\mathrm{pH}$ and ionic strength of the media ${ }^{[17]}$.

The amount of protein and sodium alginate retained on the substrate were addressed by spectroscopic measurements of the feed and permeate streams. More than $95 \%$ of the polysaccharide (SA) were retained on the top of the cellulose acetate ultrafiltration support, which represented $1.67 \mathrm{mg} \mathrm{SA} / \mathrm{cm}^{2}$ of substrate. Regarding the protein, it was observed that $65 \%$ of myoglobin was retained on the ultrafiltration support due to the hydrophilic interaction between this positively charged solute and the porous support. Due to the high value-added protein, this simple deposition method of $\mathrm{Mb}$ over the support was not used, considering the macromolecule loss of $25 \%$. It is worth to notice that $\mathrm{Mb} \mathrm{UV}$-visible spectra in the aqueous permeate were maintained, which indicates that $\mathrm{Mb}$ native primary structure was maintained even at a transmembrane pressure of 3 bar. 
The addition of calcium chloride to the sodium alginate composite membranes was investigated aiming to crosslink the polysaccharide. This feature could be interesting in the case of investigation of oxygen transport in aqueous medium, as in the development of an artificial gill. Therefore, the amount of calcium chloride was varied and the results for the water vapor swelling are presented in Table 1. Membranes were prepared in the absence of $\mathrm{Mb}$. The SA membrane with no calcium had the highest water swelling degree, as expected. Compared to the support without coating, there was an increase of 7-fold on the swelling degree, probably due to the hydrophilic sodium alginate layer. The addition of calcium chloride decreased the swelling degree, which can be reasoned in terms of the crosslinking effect of calcium ions, which were probably placed among the guluronic blocks, decreasing the macromolecular chains spacing. It was noticed that the swelling degree was lower with the

Table 1. Vapor water swelling behavior of SA composite membranes.

\begin{tabular}{cr}
\hline Sample & \multicolumn{1}{c}{ SD (\%) } \\
\hline No coated support & $6.0 \pm 0.5$ \\
Support $+\mathrm{SA}$ (no crosslinker) & $42.8 \pm 0.7$ \\
Support $+\mathrm{Ca}^{2+} / \mathrm{SA} 4 \mathrm{~g} / \mathrm{g}$ & $10.6 \pm 0.5$ \\
Support $+\mathrm{Ca}^{2+} / \mathrm{SA} 16 \mathrm{~g} / \mathrm{g}$ & $7.6 \pm 0.8$ \\
\hline
\end{tabular}

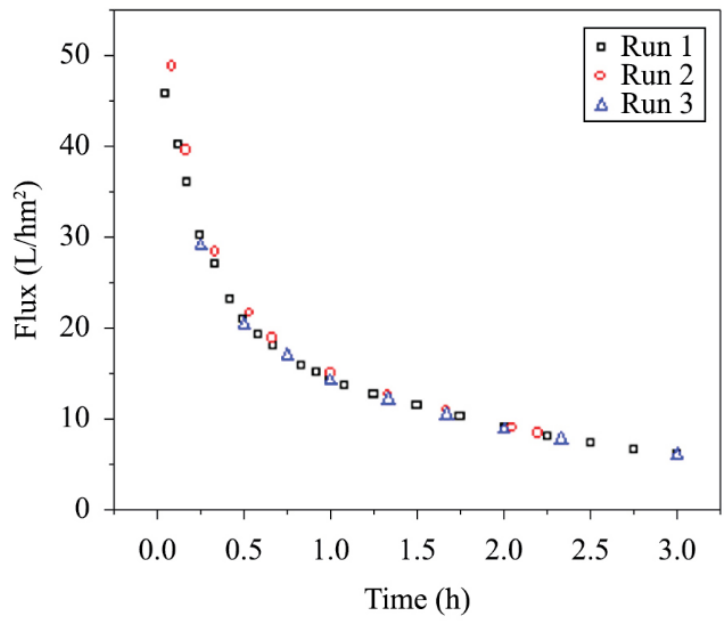

(a) increase in the calcium amount, as expected. Tests were performed in triplicates and the experimental fluctuation was around $10 \%$.

Water permeation tests showed that no significant amount of the solvent was permeated through the crosslinked membranes during 7 hours of experiment, at 3 bar. This could be explained due to the high crosslink density of the deposited layer, which decreased alginate hydrophilic character and water flux through the membrane. This result showed that the membrane was non-porous.

SEM pictures of the membranes are depicted in Figure 3. The structure of the support without coating layer is presented in Figure 3a. It showed the difference on the layers spacing from the top to the bottom. It was noticed a good interaction between the alginate layer and the support material, due to the delamination of the top layer from the non-woven material, as can be clearly seen in Figure 3b. The increase in calcium content led to the brittleness of the top layer, causing a defect on membrane surface, as can be seen in Figure 3c.

The study of myoglobin stability in ionic solutions, namely, $\mathrm{CaCl}_{2}$ and $\mathrm{FeCl}_{2}$, was accomplished in order to select the suitable conditions to perform the membrane crosslinking. The use of iron (II) as an alternative to calcium was based on its presence on myoglobin prosthetic group. The spectra for

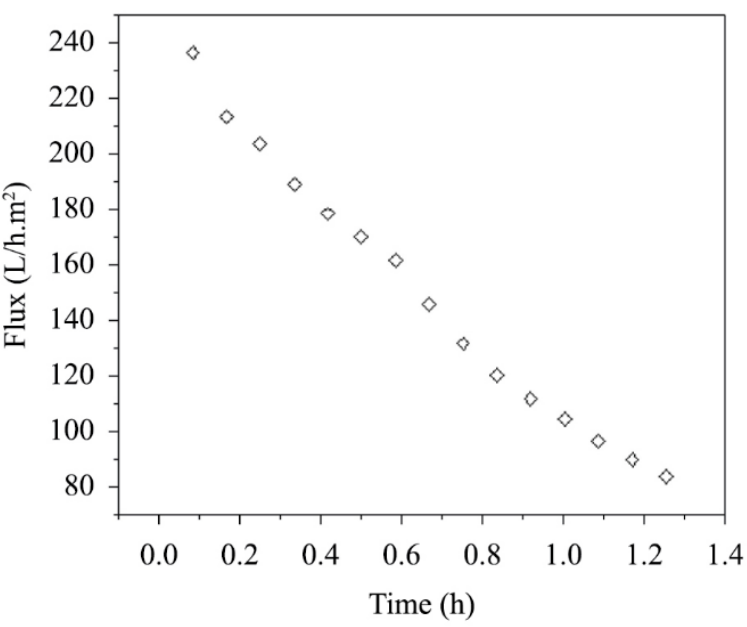

(b)

Figure 2. SA (a) and $\mathrm{Mb}(\mathrm{b})$ aqueous solution flux through cellulose acetate UF support.

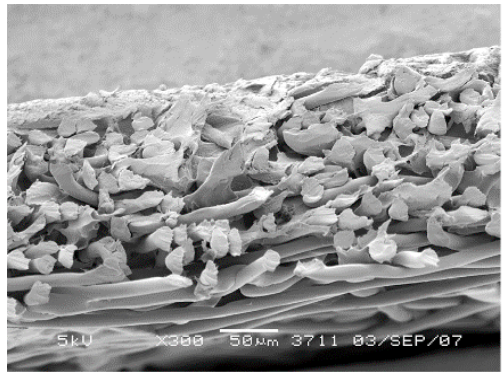

(a)

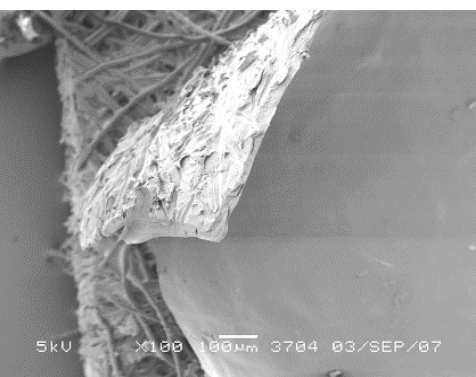

(b)

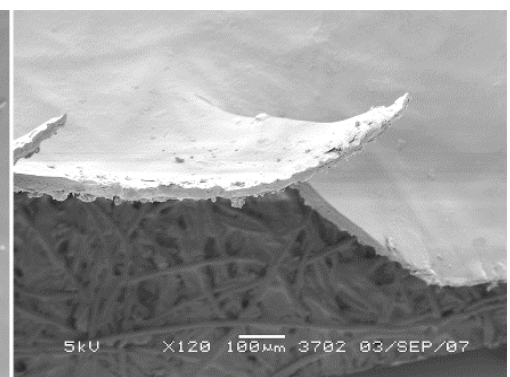

(c)

Figure 3. SEM pictures of SA composite membranes. (a) Cross section of the support without coating, (b) Delamination of SA top layer, (c) Surface of $\mathrm{Ca}^{2+} / \mathrm{SA} 16 \mathrm{~g} / \mathrm{g}$ membrane. 


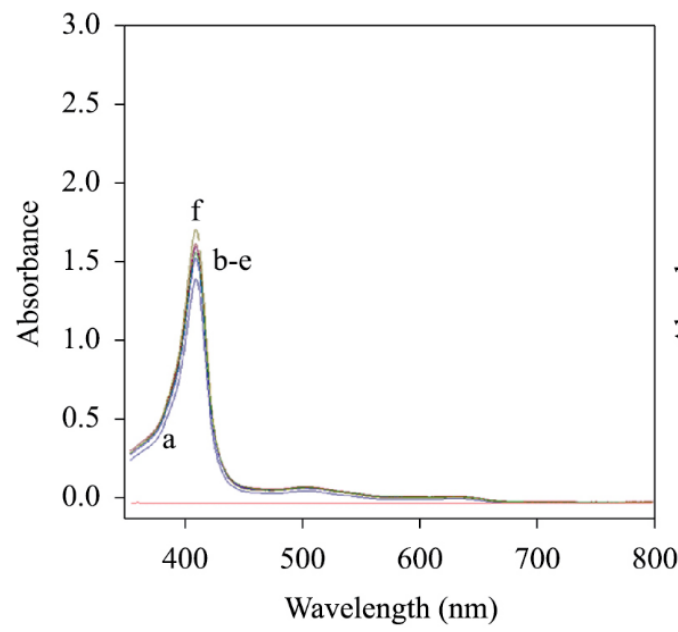

(a)

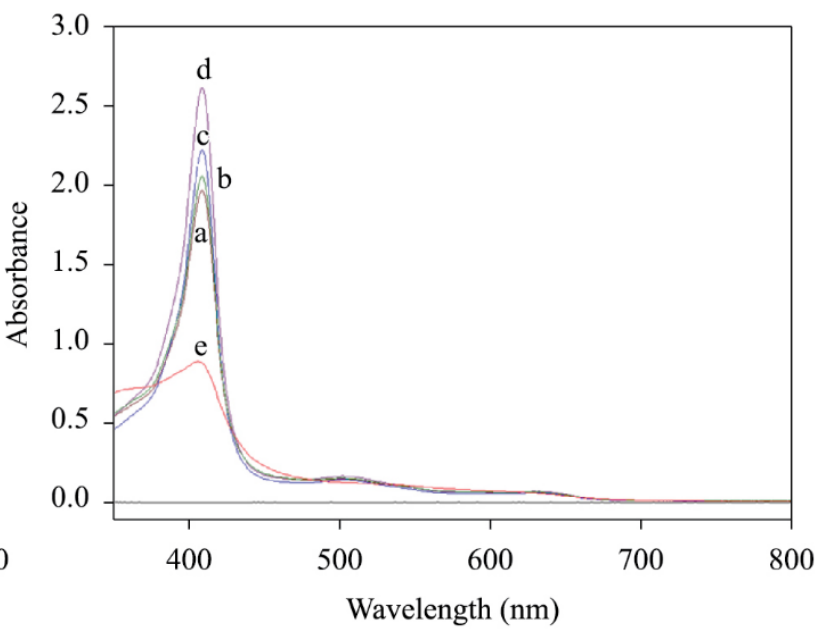

(b)

Figure 4. (a) Effect of $\mathrm{Ca}^{2+}$ on $\mathrm{Mb}$ structure 1. a) $\mathrm{CaCl}_{2} 1 \mu \mathrm{M}$, b) $\mathrm{CaCl}_{2} 0.07 \mathrm{mM}$, c) $\mathrm{CaCl}_{2} 0.13 \mathrm{mM}$, d) $\mathrm{CaCl}_{2} 0.25 \mathrm{mM}$, e) $\mathrm{CaCl}_{2} 0.5 \mathrm{mM}$, f) $\mathrm{CaCl}_{2} 1 \mathrm{mM}$. (b) Effect of $\mathrm{Fe}^{2+}$ on $\mathrm{Mb}$ structure. a) $\left.\mathrm{FeCl}_{2} 0.07 \mathrm{mM}, \mathrm{b}\right) \mathrm{FeCl}_{2} 0.13 \mathrm{mM}$, c) $\mathrm{FeCl}_{2} 0.25 \mathrm{mM}$, d) $\mathrm{FeCl}_{2} 0.5 \mathrm{mM}$, e) $\mathrm{FeCl}_{2} 1 \mathrm{mM}$.

myoglobin solutions containing calcium and iron chloride at $20^{\circ} \mathrm{C}$ are presented on Figures $4 \mathrm{a}$ and $\mathrm{b}$. The oxidation of myoglobin (change in iron II to iron III state) was noticed in both cases, since the two characteristic peaks of oxymyoglobin $(542$ and $581 \mathrm{~nm})$ were replaced by a broad peak at $630 \mathrm{~nm}$, typical of metmyoglobin form. However, it was noticed that the iron (II) also damaged the protein primary structure, since the spectrum for $1 \mathrm{mM} \mathrm{FeCl}_{2}$ solution was quite different from the standard. It was shown an increase on the absorption at the Soret region, typical of the exposition of the prosthetic group to the medium. As a result, only diluted calcium chloride solutions were investigated as crosslinker. The use of calcium chloride solution as crosslinking agent was restricted to the concentration of $1 \mu \mathrm{M}$. However, the addition of calcium ions also lead to damage on myoglobin primary structure, no matter its addition was made before or after the protein solution. The reactivation of myoglobin by sodium dithionite was no longer accomplished. Membrane color changed from brown to green, which indicated some kind of chemical reaction of iron.

As an alternative, the synthesis of membrane without crosslinker was performed, varying the amount of myoglobin added to the SA top layer. This material could be used in air fractionation, aiming the increase in oxygen flux and selectivity against nitrogen. However, the use of such membrane in aqueous media is not suitable, since it showed high swelling degree. Tests revealed that the optimum mass ratio between myoglobin and SA is $0.5 \mathrm{~g} / \mathrm{g}$. Higher protein/polysaccharide ratio lead to the clustering of protein molecules.

Gas permeation tests of the $\mathrm{Mb} / \mathrm{SA}$ membranes were conducted for oxygen and nitrogen, but the permeability was lower than 0.05 Barrer, the lower value detectable by our equipment. In order to prepare a more permeable system, we believe that the use of different crosslinking agents should be investigated, as dialdehydes, which could also increase the protein load in the composite membranes.

\section{Conclusion}

The immobilization of myoglobin in sodium alginate film was successfully accomplished in this study since protein primary structure was maintained for at least two months. The electrostatic interaction between the protein and the polysaccharide did not damage the Soret microenvironment of the biocarrier structure. This result indicated that sodium alginate is a suitable polymer for the immobilization of myoglobin.

The preparation of the composite membrane to improve the mechanical resistance of Mb-containing SA films showed high affinity between sodium alginate and the cellulose acetate UF support. The retention of the polysaccharide was higher than $95 \%$, with ca. $1.67 \mathrm{mg} \mathrm{SA} / \mathrm{cm}^{2}$. The procedure to produce non-crosslinked myoglobin-containing sodium alginate membranes was established. These results showed homogeneous membranes in which the primary native folding of myoglobin was maintained. The mass ratio between myoglobin and polymer was set in $0.5 \mathrm{~g} / \mathrm{g}$. Higher content of $\mathrm{Mb}$ caused protein clustering.

\section{Acknowledgements}

Financial support from the National Council for Scientific and Technological Development (CNPq) and the Brazilian Federal Agency for Support and Evaluation of Graduate Education (CAPES Foundation) is gratefully acknowledged. Katia C. S. Figueiredo is thankful to Membrane Technology Group, in University of Twente, The Netherlands.

\section{References}

1. Baker, R. W. (2004). Membrane technology and applications. London: John Wiley.

2. Baker, R. W. (2002). Future directions of membrane gas separation technology. Industrial \& Engineering Chemistry 
Research, 41(6), 1393-1411. http://dx.doi.org/10.1021/ ie 0108088 .

3. Figoli, A., Sager, W. F. C., \& Mulder, M. H. V. (2001). Facilitated oxygen transport in liquid membranes: review and new concepts. Journal of Membrane Science, 181(1), 97-110. http://dx.doi.org/10.1016/S0376-7388(00)00508-1.

4. Shentu, B., \& Nishide, H. (2003). Facilitated oxygen transport membranes of picket-fence cobaltporphyrin complexed with various polymer matrixes. Industrial \& Engineering Chemistry Research, 42(24), 5954-5958. http://dx.doi.org/10.1021/ ie020770e.

5. Suzuki, T., Yasuda, H., Nishide, H., Chen, X. S., \& Tsuchida, E. (1996). Electrochemical measurement of facilitated oxygen transport through a polymer membrane containing cobaltporphyrin as a fixed carrier. Journal of Membrane Science, 112(2), 155160. http://dx.doi.org/10.1016/0376-7388(95)00291-X.

6. Nishide, H., Tsukahara, Y., \& Tsuchida, E. (1998). Highly selective oxygen permeation through a poly(vinylidene dichloride)-cobalt porphyrin membrane: hopping transport of oxygen via the fixed cobalt porphyrin carrier. The Journal of Physical Chemistry B, 102(44), 8766-8770. http://dx.doi. org/10.1021/jp9816317.

7. Sugawara, Y., Matsuoka, A., Kaino, A., \& Shikama, K. (1995). Role of globin moiety in the autoxidation reaction of oxymyoglobin: effect of $8 \mathrm{M}$ urea. Biophysical, 69(2), 583-592. http://dx.doi.org/10.1016/S0006-3495(95)79932-5. PMid:8527673.

8. Ferraz, H. C. (2003). Membranas de transporte facilitado para separação de oxigênio utilizando biotransportadores (Doctor Thesis). Universidade Federal do Rio de Janeiro, Rio de Janeiro.

9. Draget, K. I., Smidsrod, O., \& Skjak-Braek, G. (2005). Polysaccharides in the food industry: properties, production, and patents. Weinhein: John Wiley.

10. van de Ven, W. J. C., van't Sant, K., Punt, I. G. M., Zwijnenburg, A., Kemperman, A. J. B., van der Meer, W. G. J., \& Wessling, M. (2008). Hollow fiber dead-end ultrafiltration: Influence of ionic environment on filtration of alginates. Journal of Membrane Science, 308(1-2), 218-229. http://dx.doi. org/10.1016/j.memsci.2007.09.062.
11. Carvalho, R. B., Borges, C. P., \& Nóbrega, R. (2001). Formação de membranas planas celulósicas por espalhamento duplo para os processos de nanofiltração e osmose inversa. Polímeros: Ciência e Tecnologia, 11(2), 65-75. http://dx.doi.org/10.1590/ S0104-14282001000200008.

12. Shi, Y. Q., Wang, X. W., Chen, G. W., Golemme, G., Zhang, S. M., \& Drioli, E. (1998). Preparation and characterization of high-performance dehydrating pervaporation alginate membranes. Journal of Applied Polymer Science, 68(6), 959-968. http:// dx.doi.org/10.1002/(SICI)1097-4628(19980509)68:6<959::AIDAPP9>3.0.CO;2-G.

13. Dubois, M., Gilles, K. A., Hamilton, J. K., Rebers, F. A., \& Smith, F. (1956). Colorimetric method for determination of sugars and related substances. Analytical Chemistry, 28(3), 350-356. http://dx.doi.org/10.1021/ac60111a017.

14. Hargrove, M. S., Wilkinson, A. J., \& Olson, J. S. (1996). Structural factors governing hemin dissociation from metmyoglobin. Biochemistry, 35(35), 11300-11309. http://dx.doi.org/10.1021/ bi960372d. PMid:8784184.

15. Ordway, G. A., \& Garry, D. J. (2004). Myoglobin: an essential hemoprotein in striated muscle. The Journal of Experimental Biology, 207(Pt 20), 3441-3446. http://dx.doi.org/10.1242/ jeb.01172. PMid: 15339940 .

16. Marmo Moreira, L., Lima Poli, A., Costa-Filho, A. J., \& Imasato, H. (2006). Pentacoordinate and hexacoordinate ferric hemes in acid medium: EPR, UV-Vis and CD studies of the giant extracellular hemoglobin of Glossoscolex paulistus. Biophysical Chemistry, 124(1), 62-72. http://dx.doi.org/10.1016/j. bpc.2006.05.030. PMid:16814451.

17. Mahlicli, F. Y., Altinkaya, S. A., \& Yurekli, Y. (2012). Preparation and characterization of polyacrylonitrile membranes modified with polyelectrolyte deposition for separating similar sized proteins. Journal of Membrane Science, 415-416(1), 383-390. http://dx.doi.org/10.1016/j.memsci.2012.05.028.

Received: June 26, 2014

Revised: Oct. 12, 2014 Accepted: Nov. 18, 2014 